\title{
BRAZIL, REIDY E A ARQUITETURA BRASILEIRA DO SÉCULO 2O: DOIS MODERNOS MARCANTES
}

BONDUKI, Nabil (Org). Affonso Eduardo Reidy. Lisboa, Portugal: Editorial Blau; Instituto Lina Bo e P. M. Bardi, 2000, 216p. (il.).

CONDURO, Roberto. Vital Brazil. São Paulo: Cosac \& Naify Edições, 2000. 126p. (il.).

\section{Sheila Walbe Ornstein}

Vice-diretora, professora titular do Departamento de Tecnologia da Arquitetura da FAUUSP e pesquisadora sênior do Núcleo de Pesquisa em Tecnologia da Arquitetura e Urbanismo da Universidade de São Paulo - NUTAU/USP.

As editoras Cosac \& Naify e a portuguesa Blau, associada ao Instituto Lina Bo e P. M. Bardi, no ano passado, brindaram-nos com duas obras muito cuidadosas a respeito dos arquitetos modernos Affonso Eduardo Reidy (1909-1964) e Álvaro Vital Brazil (1909-1997). Ambos cursaram arquitetura na Escola Nacional de Belas Artes no Rio de Janeiro, na mesma época (Reidy no período 1926-1930 e Brazil no período 1929-1933, sendo que este último também cursou paralelamente engenharia civil na Escola Politécnica). Receberam, portanto, influências socioeconômico-políticas, além daquelas referentes aos princípios da arquitetura moderna, discussões estas efervescentes na Europa (Congressos Internacionais de Arquitetura Moderna - CIAM) e no país (Instituto de Arquitetos do Brasil - $\mid A B$ ), muito próximas e semelhantes.

As idéias, os projetos e as obras edificadas desses dois arquitetos, agora criteriosa e cronologicamente registradas a partir das pesquisas de Bonduki (Reidy) e de Conduro (Brazil), são peças fundamentais no quebra-cabeça da arquitetura brasileira do século 20 , faltantes até o momento para a melhor compreensão da nossa boa arquitetura moderna.

Nesta resenha conjunta, não se pretende fazer comparações críticas em relação à obra de ambos, mas sim, destacar a importância de suas atividades profissionais aos graduandos e pós-graduandos em arquitetura e aos estudiosos da arquitetura moderna e do seu impacto na construção e na transformação de nossas cidades nos últimos 80 anos. De fato, embora Reidy e Brazil tenham gerado seus exemplos mais expressivos de arquitetura, na mesma época, tiveram trajetórias distintas de vida. Reidy, apesar da morte prematura (aos 55 anos), desenvolveu prioritariamente projetos de toda a ordem (dos edifícios aos espaços públicos) relevantes para a cidade do Rio de Janeiro e a sua qualidade urbana. Brazil, por sua vez, apresenta projetos - especialmente de edifícios - em muitas cidades brasileiras, mas um conjunto de obras mais contido, embora marcado pela qualidade arquitetônica.

Em ambos os casos, é reconfortante para nós ainda poder constatar in situ, vários dos belos exemplos relacionados nos livros. Provavelmente, por se tratarem de 
obras do século 20 - portanto relativamente recentes - e talvez por receber algum tipo de manutenção do poder público ou de seus proprietários, em vários casos ainda não estão sujeitos à degradação acelerada visível e muito freqüente nas nossas cidades. Enfim, são, ainda, em várias circunstâncias, convites à visitação, especialmente a gerações de arquitetos formados nas últimas três décadas, como esta resenhadora, para quem muitas delas fazem parte das memórias de infância sobre a vida em grandes cidades como São Paulo e Rio de Janeiro.

Dentre as obras de Reidy, o trabalho de Bonduki destaca:

1936-1942 - a participação na equipe projetista do edifício do Ministério da Educação e Saúde, liderada por Lúcio Costa (Rio de Janeiro); 1946 - projeto do Conjunto Residencial Pedregulho; participação como urbanista, ao final da década de 40, da equipe projetista do aterro e Parque do Flamengo, sob a liderança da arquiteta Maria Carlota de Macedo Soares; 1953 - Museu de Arte Moderna (MAM) do Rio de Janeiro, no Aterro do Flamengo (ver também literatura complementar, a obra de Nobre sobre a engenheira Carmen Portinho); chama ainda a atenção os planos urbanísticos e os projetos para conjuntos habitacionais, desenvolvidos por Reidy, como servidor público da cidade (Distrito Federal) do Rio de Janeiro.

Dentre as obras de Brazil, o trabalho de Conduro destaca:

1936 - o Edifício Esther, junto à praça da República em São Paulo, com seu programa misto, incluindo lojas, salas para escritórios e consultórios e apartamentos de vários tamanhos; 1942 - Edifício-sede do Instituto Vital Brazil (pai do arquiteto e no início do século 20, diretor do Instituto Butantā); 1943 - abrigos para o Serviço Especial de Mobilização de Trabalhadores, para a Amazônia - SEMTA, os quais foram construidos em situação emergencial, com os materiais disponíveis na região como a palha de babaçu, de carnaúba, ou buriti; 1953 - Edifício Silvestre, Rio de Janeiro, residencial de três pavimentos, apoiado sobre pilotis, em terreno de grande declividade e passarelas de acesso; 1958 - Edifício Tiradentes (sede do Banco da Lavoura de Minas Gerais), Recife, afastado das edificações vizinhas e com quebra-sóis constituídos de grelhas fixas de concreto; 1964-1974 - Estaleiro da EMAQ (Engenharia e Máquinas S.A.), situado em aterro na Baía de Guanabara, Rio de Janeiro. Neste caso, chama a atenção a qualidade das obras no que diz respeito à apropriação do partido arquitetônico e do partido estrutural, bem como as preocupações específicas do arquiteto com as condições locais de conforto térmico.

Em um momento em que a arquitetura contemporânea brasileira passa por um longo período de transição, no qual as influências nacionais, regionais e as internacionais resultam em bons e maus exemplos edificados, nem sempre significando qualidades arquitetônica e urbanística irrepreensíveis e que são implantados em cidades, cujos limites da formalidade são pouco conhecidos ou considerados, a oportunidade de estudar de modo sistemático as obras de Reidy e Brazil - cujos partidos arquitetônico e urbanístico levam em consideração a qualidade de vida dos habitantes da cidade e dos usuários dos espaços públicos e privados - é muito bemvinda. 
Para leitura complementar, segue um conjunto de obras recentemente publicadas que não só resgatam a arquitetura moderna em distintas cidades brasileiras, mas também a arquitetura moderna portuguesa. Esta última sofreu grande influência da primeira. É importante destacar, no entanto, que esta lista não tem a pretensão de ser exaustiva, mas apenas complementar a resenha, demonstrando a repercussão dos princípios da arquitetura moderna, não em cidades como São Paulo e no Rio de Janeiro, mas também em outras, época de porte menos expressivo no contexto urbano nacional, como o caso dentre outros, de Londrina, Pelotas e Campo Grande. Estas obras, várias vezes contextualizam os exemplos, projetos e edifícios em termos socioeconômico e político, muitas vezes descrevem as tipologias e tecem análises críticas.

ALBUQUERQUE, Roberto Portugal. Caderno dos riscos originais: Projeto do Edifício da FAUUSP na Cidade Universitária. São Paulo: Faculdade de Arquitetura e Urbanismo da Universidade de São Paulo, 1998.

ARTIGAS, Rosa (Org.). Paulo Mendes da Rocha. São Paulo: Cosac \& Naify, 2000.

ARTIGAS, Vilanova. Caminhos da arquitetura. São Paulo: Cosac \& Naify Edições, 1999

CASTRIOTA, Leonardo Barci (Org.). Arquitetura da modernidade. Belo Horizonte, Minas Gerais: Editora da Universidade Federal de Minas Gerais - Instituto de Arquitetos do Brasil - Departamento de Minas Gerais, 1998.

MOURA, Rosa Maria Garcia Rolim de, SCHLEE, Andrey Rosenthal. 100 imagens da arquitetura pelotense. Pelotas, Rio Grande do Sul: Pallotti, 1998.

NOBRE, Ana Luiza. Carmen Portinho. Rio de Janeiro: Relume Dumará Editora e Prefeitura do Rio, 1999 (Perfis do Rio).

SEGAWA, Hugo. Arquitetura no Brasil 1900-1990. Sāo Paulo: Editora da Universidade de Sāo Paulo, 1997.

SHIMBA, Otavio Yassuo, UREN, Flávio Henrique da Rosa. Londrina cidade cenário. Londrina, Paraná: Midiograf, s.d.

TOSTÕES, Ana, BECKEN, Annette, WARG, Wilfried. Arquitectura do século XX: Portugal. Frankfurt, Alemanha: Deutsches Architektur - Museum, Prestel, 1998.

TOSTÕES, Ana. Os verdes anos na arquitectura portuguesa dos anos 50. Porto, Portugal: Faculdade de Arquitectura da Universidade do Porto, 1997. 